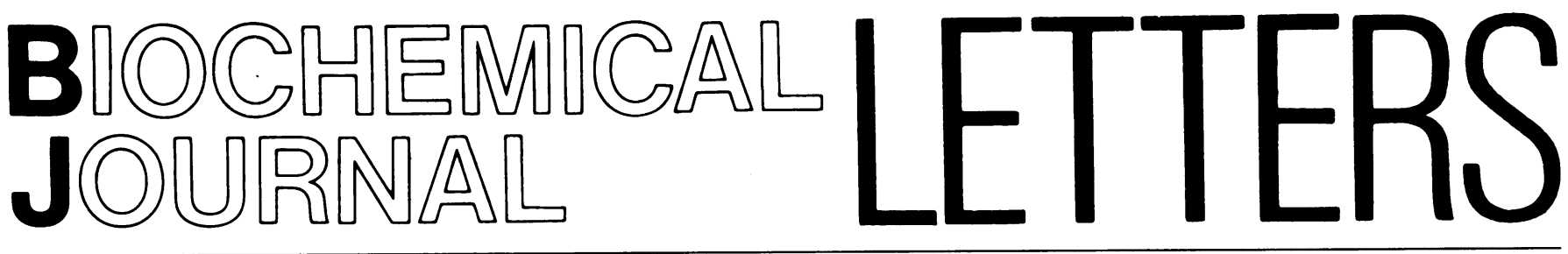

\section{On the mechanism of $\mathrm{OH}^{\bullet}$ scavenger action}

$\mathrm{O}_{2}$ in aqueous solution is fairly unreactive and many of its damaging effects have been attributed to formation of hydroxyl radical, $\mathrm{OH}^{*}$ (for reviews see Halliwell \& Gutteridge, 1984; Slater, 1984). The damage observed, however, can be brought about by a number of oxidizing species not identical with $\mathrm{OH}^{\bullet}$, including perferryl radical (Svingen et al., 1978) or ferryl radical (Rush \& Koppenol, 1986). The involvement of $\mathrm{OH}^{*}$ in a given system is frequently inferred by the prevention of the studied reaction by known scavengers of $\mathrm{OH}^{*}$ such as mannitol, formate, thiourea and ethanol (Tien et al., 1982; Gutteridge, 1984; Halliwell \& Gutteridge, 1985).

If we search the literature on the use of $\mathrm{OH}^{\bullet}$ scavengers in biological systems, we find that the protective effect provided by these scavengers is not necessarily what is expected from chemically determined rate constants. Several hypotheses were suggested to explain the reason for these deviations (Gutteridge, 1984, 1987; Henglein \& Kormann, 1985; Moorhouse et al., 1985). Recently we have conducted a study on the mechanism of action of some of the classical $\mathrm{OH}^{\bullet}$ scavengers.

We studied the effect of $\mathrm{OH}^{*}$ scavengers both on the formation of thiobarbituric acid-reactive material from deoxyribose caused by the Fenton reaction $\left(\mathrm{Fe}^{2+}+\mathrm{H}_{2} \mathrm{O}_{2}\right)$ and on $\mathrm{Fe}^{2+}$ oxidation by $\mathrm{H}_{2} \mathrm{O}_{2}$. The buffering species Mes and Mops, which have low affinities for metals (Good et al., 1966), were used to facilitate the interpretation of these metal ion dependent reactions. The concentration of the buffer was kept rather low $(5 \mathrm{~mm})$ to limit the possible interference due to its reaction with $\mathrm{OH}^{\bullet}$. Damage to $2.8 \mathrm{~mm}$-deoxyribose by Fenton reaction $\left(200 \mu \mathrm{M}-\mathrm{H}_{2} \mathrm{O}_{2}\right.$ and $\left.150 \mu \mathrm{M}-\mathrm{FeCl}_{2}\right)$ was detected by thiobarbituric acid-reactive material according to Tien $e t$ al. (1982). $\mathrm{Fe}^{2+}$ determination was made by the $o$-phenanthroline method of Mahler \& Elowe (1954).

In the absence of $\mathrm{OH}^{*}$ scavengers, $\mathrm{OH}^{*}$ damage to deoxyribose is higher at $\mathrm{pH} 6$ compared with $\mathrm{pH} 7$ and 7.4. At acid pH, deoxyribose is apparently able to inhibit $\mathrm{Fe}^{2+}$ oxidation by $\mathrm{H}_{2} \mathrm{O}_{2}$. This effect of the sugar is greatly decreased at $\mathrm{pH} 7$ and 7.4. Deoxyribose is known to bind iron salts (Gutteridge, 1987) and $\mathrm{Fe}^{2+}$ bound on this detector molecule would catalyse a site-specific production of $\mathrm{OH}^{*}$. This system thus generates $\mathrm{OH}^{*}$ on the substrate and there immediately converts the resulting radical to stable product by oxidation by the metal just oxidized in the $\mathrm{OH}^{-}$-forming process. In the presence of deoxyribose an apparent decreased $\mathrm{Fe}^{2+}$ oxidation by Fenton reaction would occur. Oxidations of this type were postulated in the original schemes of Haber \& Willstätter (1931), confirmed by Walling (1975). The effect of $\mathrm{pH}$ can be ascribed to a different absorption of

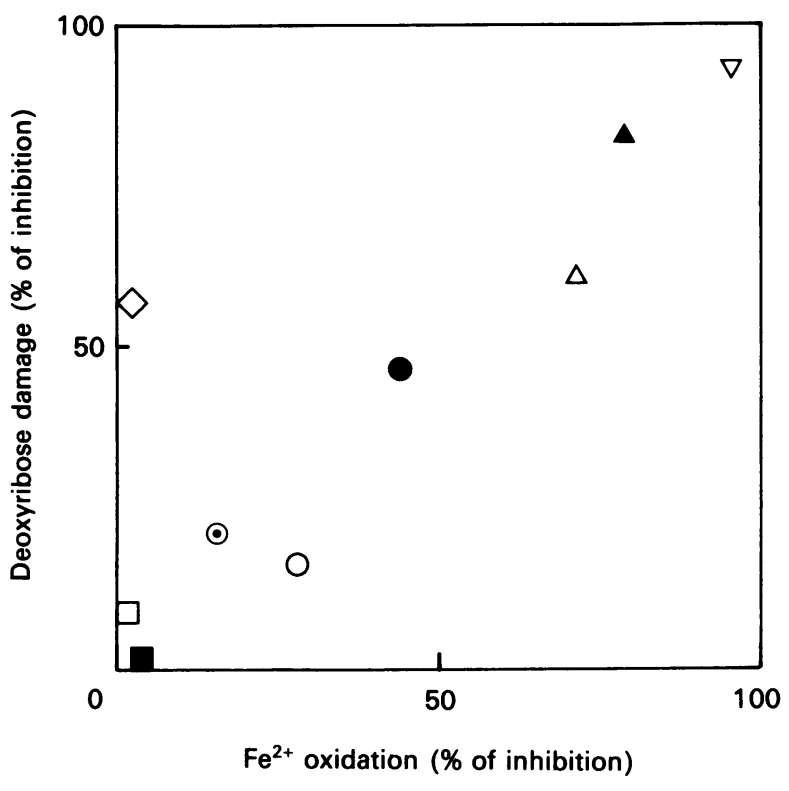

Fig. 1. Inhibition of deoxyribose damage and $\mathrm{Fe}^{2+}$ oxidation by $\mathrm{OH}^{\prime}$ scavengers

17 mM-Ethanol (O), 15 mm-butan-1-ol (๑), 20 mM-methanol $(\circlearrowleft), 20 \mathrm{~mm}$-formate $(\diamond), 0.1 \mathrm{~mm}-(\triangle)$ and $1 \mathrm{~mm}$ $(\nabla)$ thiourea, $10 \mathrm{~mm}$-mannitol $(\Delta), 40 \mathrm{~mm}$-acetate $(\square)$ and $10 \mathrm{~mm}$-benzoate $(\square)$ were used.

$\mathrm{Fe}^{2+}$ to the substrate detector molecule due to a replacement of bound ligand by hydroxyl anions.

We then studied $\mathrm{OH}^{\circ}$ scavenger effects. When the experiments were conducted in Mes buffer, $\mathrm{pH} \mathrm{6,} \mathrm{a} \mathrm{close}$ relationship (Fig. 1) was found between the effects of $\mathrm{OH}^{*}$ scavengers on the two parameters measured. Damage to deoxyribose was inhibited to various extents by all $\mathrm{OH}^{-}$scavengers tested (ethanol, butan-1-ol, methanol, formate, thiourea and mannitol) but not by benzoate and acetate. The inhibition of $\mathrm{Fe}^{2+}$ oxidation by $\mathrm{OH}^{\cdot}$ scavengers was qualitatively and quantitatively similar to that exerted on deoxyribose damage. Formate was the only exception. The decreased oxidation of $\mathrm{Fe}^{2+}$ observed in these experimental conditions was neither due to inhibition by $\mathrm{OH}^{*}$ scavengers of the Fenton reaction nor to a direct reaction of $\mathrm{OH}^{\cdot}$ scavengers with $\mathrm{H}_{2} \mathrm{O}_{2}$. This was demonstrated by determining $\mathrm{H}_{2} \mathrm{O}_{2}$ concentration by the horseradish peroxidase reaction of $\mathrm{H}_{2} \mathrm{O}_{2}$ with the fluorescent dye scopoletin (Loschen et al., 1971). These results contrast with the reported reaction between thiourea and $\mathrm{H}_{2} \mathrm{O}_{2}$ (Cederbaum et al., 1979) which was suggested to explain the abnormal behaviour of thiourea as $\mathrm{OH}^{*}$ scavenger (Moorhouse et al., 1985). To explain the correlation between $\mathrm{OH}^{*}$ scavenger effects on deoxyribose damage and $\mathrm{Fe}^{2+}$ oxidation, a mechanism 
similar to that suggested for deoxyribose can be invoked. The $\mathrm{OH}^{\cdot}$ scavengers would bind the metal and compete for it with the detector molecule. This would result in the decreased site-specific generation of $\mathrm{OH}^{\cdot}$ on deoxyribose, in the formation of the $\mathrm{OH}^{*}$ scavenger radical and in its successive oxidation by the $\mathrm{Fe}^{3+}$ generated by the Fenton reaction. This mechanism explains the apparent reaction of thiourea with $\mathrm{H}_{2} \mathrm{O}_{2}$ reported by Cederbaum et al. (1979), as in that paper $\mathrm{H}_{2} \mathrm{O}_{2}$ concentration was measured by the thiocyanate method, i.e. measuring $\mathrm{Fe}^{3+}$ produced by Fenton reaction. The lack of correlation observed in the presence of formate may be due to the insufficient reactivity to induce $\mathrm{Fe}^{3+}$ of the secondary radical produced by $\mathrm{OH}^{\cdot}$ attack on this scavenger. This agrees with the known inertness of carbonyl radicals to oxidation by $\mathrm{Fe}^{3+}$ (Walling, 1975). The effects of $\mathrm{OH}^{\cdot}$ scavengers on deoxyribose damage and $\mathrm{Fe}^{2+}$ oxidation are both $\mathrm{pH}$-dependent. When the reactions are conducted in Mops buffer, $\mathrm{pH} 7$ or 7.4, a parallel decreased inhibition, by all $\mathrm{OH}^{*}$ scavengers, of the two phenomena is observed. However the dependence of the effects of the various $\mathrm{OH}^{*}$ scavengers on the $\mathrm{pH}$ greatly differs. A rough order of sensitivity is ethanol, butan-1-ol, methanol, formate $>$ thiourea $>$ mannitol.

In summary, our results indicate that the ability of classical $\mathrm{OH}^{*}$ scavengers to inhibit deoxyribose degradation correlates with their ability to decrease $\mathrm{Fe}^{2+}$ oxidation by $\mathrm{H}_{2} \mathrm{O}_{2}$. If the mechanism that can explain the present findings is that proposed by Haber \& Willstätter (1931) and by Walling (1975), some conclusions can be drawn. Not only mannitol and thiourea but other classical $\mathrm{OH}^{*}$ scavengers can affect $\mathrm{OH}^{*}$ dependent damage to detector molecules by binding $\mathrm{Fe}^{2+}$. All these $\mathrm{OH}^{\cdot}$ scavengers act predominantly by this mechanism, as they are practically unable to protect against the damage produced by $\mathrm{OH}^{\cdot}$ radical generated at specific sites (Gutteridge, 1984) in experimental conditions where they do not interact with $\mathrm{Fe}^{2+}$. As it appears more and more evident that $\mathrm{OH}^{*}$ generation by the Fenton reaction in biological systems is site-specific, the suggested use of $\mathrm{OH}^{\cdot}$ scavengers to indicate the involvement of $\mathrm{OH}^{-}$in such systems (Halliwell \& Gutteridge, 1985) becomes questionable.

\section{Bruna TADOLINI and Luciana CABRINI}

Dipartimento di Biochimica, Universita' di Bologna, Via Irnerio 48, 40126 Bologna, Italy

Cederbaum, A. I., Dicker, E., Rubin, E. \& Cohen, G. (1979) Biochemistry 18, 1187-1191

Good, N. E., Winget, G. D., Winter, W., Connolly, T. N., Izawa, S. \& Singh, M. M. (1966) Biochemistry 5, 467-477

Gutteridge, J. M. C. (1984) Biochem. J. 224, 761-767

Gutteridge, J. M. C. (1987) Biochem. J. 243, 709-714

Haber, F. \& Willstätter, R. (1931) Chem. Ber. 64, 2844-2856

Halliwell, B. \& Gutteridge, J. M. C. (1984) Biochem. J. 219, 1-14

Halliwell, B. \& Gutteridge, J. M. C. (1985) in Handbook of Methods for Oxygen Radical Research (Greenwald, R. A., ed.), pp. 177-180, CRC Press, Boca Raton, FL

Henglein, A. \& Kormann, C. (1985) Int. J. Radiat. Biol. 48, 251-258

Loschen, G., Elohe, L. \& Chance, B. (1971) FEBS Lett. 18, 261-264

Mahler, H. R. \& Elowe, D. G. (1954) J. Biol. Chem. 210, 165-179
Moorhouse, C. P., Halliwell, B., Grootveld, M. \& Gutteridge, J. M. C. (1985) Biochim. Biophys. Acta 843, 261-268

Rush, J. D. \& Koppenol, W. H. (1986) J. Biol. Chem. 261, 6730-6733

Slater, T. F. (1984) Biochem. J. 222, 1-15

Svingen, B. A., O'Neal, F. O. \& Aust, S. D. (1978) Photochem. Photobiol. 28, 803-809

Tien, M., Svingen, B. A. \& Aust, S. D. (1982) Arch. Biochem. Biophys. 216, 142-151

Walling, C. (1975) Acc. Chem. Res. 8, 125-131

Received 14 January 1988

\section{The deoxyribose assay: an assay both for 'free' hydroxyl radical and for site-specific hydroxyl radical production}

The interaction of iron ions with hydrogen peroxide in biological systems can lead to formation of a highlyreactive tissue-damaging species that is thought to be the hydroxyl radical, ${ }^{\circ} \mathrm{OH}[1,2]$. Various reactive iron-oxygen complexes may also exist, such as ferryl, perferryl and $\mathrm{Fe}^{2+} / \mathrm{Fe}^{3+} / \mathrm{O}_{2}$ species (reviewed in [3-5]). There has thus been considerable interest in the development of methods for assaying ${ }^{\circ} \mathrm{OH}$ and related species in biological systems (reviewed in [6]).

The pentose sugar 2-deoxyribose is attacked by ${ }^{\circ} \mathrm{OH}$ radicals to yield a mixture of products (reviewed in [7]). On heating with thiobarbituric acid at low $\mathrm{pH}$, some or all of these products react to form a pink chromogen that can be measured by its absorbance at $532 \mathrm{~nm}$; this chromogen is indistinguishable from a thiobarbituric acid-malondialdehyde (TBA-MDA) adduct [8]. Generation of a TBA-MDA adduct from deoxyribose was thus introduced in $1981[8,9]$ as a simple assay for ${ }^{\circ} \mathrm{OH}$ generation in biological systems, provided that suitable control experiments are performed. The assay has been widely used [8-10].

If deoxyribose is incubated with $\mathrm{H}_{2} \mathrm{O}_{2}$ and an $\mathrm{Fe}^{2+}$ EDTA complex (or an $\mathrm{Fe}^{3+}$-EDTA complex in the presence of a reducing agent such as ascorbate or superoxide, $\mathrm{O}_{2}^{-}$), the resulting deoxyribose degradation is inhibited by any added scavenger of ${ }^{\circ} \mathrm{OH}$ to an extent that depends only on the concentration of scavenger relative to deoxyribose, and on the scavenger's secondorder rate constant for reaction with $\mathrm{OH}$ [11-13]. It seems that, when ${ }^{\circ} \mathrm{OH}$ is generated by reaction of $\mathrm{Fe}^{2+}$ EDTA with $\mathrm{H}_{2} \mathrm{O}_{2}$, any ${ }^{\circ} \mathrm{OH}$ that escapes scavenging by the EDTA itself [14] enters 'free solution' and is equally accessible to deoxyribose and to any added scavenger. Indeed, the deoxyribose assay in the presence of $\mathrm{Fe}^{3+}$ EDTA, $\mathrm{H}_{2} \mathrm{O}_{2}$ and a reducing agent has been proposed as a simple 'test-tube' method for determining rate constants for the reaction of substrates with $\mathrm{OH}[11,12]$.

If deoxyribose is incubated with $\mathrm{H}_{2} \mathrm{O}_{2}$ and $\mathrm{Fe}^{2+}$ (or $\mathrm{Fe}^{3+}$ plus a reductant) in the absence of EDTA, it is still degraded into products that can react to form a TBA-MDA chromogen $[6,8,9]$. However, some $\cdot \mathrm{OH}$ scavengers (such as ethanol, formate, dimethyl sulphoxide and Hepes) no longer inhibit the deoxyribose degradation whereas others, such as mannitol, thiourea and hydroxychloroquine, still do $[11,13,15]$. Two possible explanations of this observation have been advanced. 